\title{
The Psychological Perspective of Immigration and Resettlement in Israel: Separation vs. Severance
}

\author{
Dan Bar-On, Michal Sadeh, and Daniela Treister ${ }^{1}$
}

\section{Introduction}

Israeli society is basically composed of accumulating waves of immigrants (Eilon 1976). Though large portions of the Israeli society are by now second and third generation of immigrants, one can still ask: When do people feel that they have finally resettled and feel "integrated" ?2 Does this process end with the first generation of immigrants? Or, alternatively, what does "becoming an Israeli" actually mean, when and how does it happen? These questions were answered differently over the years (Segev 1986, 1992). Initially a collective norm was developed defining an Israeli by external features. One was included by looking healthy ("like a Sabra"), talking Hebrew without a foreign accent, performing physical work (in the earlier days), having a social, economic, and lately also educational status; or originating from or being socialized in certain exclusive collectives (certain branches of youth movements, army units, neighbourhoods). However, over the years these norms have changed and have become vaguer. Does this change mean a "retreat" in terms of resettlement and integration, as some people evaluate it, or is it a movement "forward" as others have suggested (Segev 1992)? These differences in the narrative are part of our concern in this paper.

Generally, people tended to avoid delving too deeply into these questions during the warfare with the Arab states, because their propaganda was aimed directly at this point: "Immigrants (outsiders)! Go back to your home countries." The Israeli discourse, struggling with these attacks, pro-

Dan Bar-On, Michal Sadeh, and Daniela Treister are at the Department of Behavioural Sciences, Ben-Gurion University of the Negev, Israel.

claimed a "healthy" and "well-rooted" society (Eilon 1976) which returned to its old homeland and rebuilt it. However, the beginning of the peace process, easing the need for collective identity through a common enemy, enabled us to re-examine to what extent this claim is valid, and what it is actually referring to or pointing at.

In this paper, we wish to add a psychological perspective to the concept of resettlement, discussing specifically the Israeli case. We claim that the traditional Israeli approach to resettlement (and self-determination of identity) was basically a non-psychological one, successful in the short run but problematic in the long run. We wish to show that the difference between the

about it, behaving as if it had happened, measuring external aspects of social and economic status or language, and ignoring less obvious but deeper psychological meanings (Aroian 1990, Levi 1989). The image used to describe the difference between severance and separation is an image of a tree and its roots: one can look like a huge tree and have tiny roots, or one may look like a small tree and develop deep roots. The first may grow well in a dense forest (collective), but is in danger of being torn out when standing alone, especially during a severe storm. The second may not look so beautiful, but is better accustomed to the harsh conditions of life in this area (also when being left alone). Big

\section{The act of severance, of breaking one's ties with the original \\ home, accompanied by a lack of psychological sophistication, had historical, ideological, and political reasons in the Israeli case.}

two approaches concentrates around the notion of severance versus separation (Bar-On 1994). The act of severance, of breaking one's ties with the original home, accompanied by a lack of psychological sophistication, had historical, ideological, and political reasons in the Israeli case, which we will discuss in some detail.

In contrast, the psychological perspective views the process of separation as much more time- and energy-consuming. It demands a slow, back-and-forth movement from the old into the new frame of reference. It implies "working through" and "mourning" (Bar-On 1994). It suggests that resettlement is not a singular act, feeling, or thought, but rather a process which has many ups and downs, until it ripens as a new internal frame of reference (of time, place, and people). Its inadequate processing would result in a pseudo resettlement: talking trees with deep roots take many generations to develop. Still, even trees can slowly change their rootstock, even artificially, through "support grafting" (Bar-On 1994).

At the same time, severance was never proclaimed as a goal: it became an undercurrent, a tacit given. An example: the Hebrew language became a collective symbol of Zionism. Within the manifest discourse, it was the sign of continuity and reconnectedness to the promised land. It was also the miraculous revival of a language from the holy books in everyday life, unheard of in any other culture or history of a people (Eilon 1976). However, in reality it also implied severance from one's own home culture and language. It meant that one should speak in a language different from one's own. It also implied that the grandparents from abroad would not be able to communicate with their grandchildren. One 
could still justify it as a necessary break from the old tradition in order to build a common frame of reference in Israel. However, our argument is that, since it was done abruptly (which was the case for many families or individual immigrants), it brought about severance rather than separation in the process of resettlement.

We will discuss the possibility of adding to the reality of severance a psychological separation perspective, by re-establishing physical contact and emotional ties with what one severed from years ago.

Our examples are based on interviews, which two of the authors (Sadeh and Treister) have conducted, with middle-aged Israelis who have revisited their original homelands (in Morocco and Eastern Europe) some forty years after they had left them. In these cases, there was no possibility to enter those countries all these years, because the political ties between these countries and Israel were severed. We will concentrate on the difficulties in acknowledging the need for constructing a process of separation where severance had occurred, and was assumed to have "done with" emotional ties to the past.

\section{Cutting off the Old Roots: The Israeli Sources of Severance}

In the Israeli case, the act of severance of immigrants from their home culture had five independent (though interacting) sources, which could be identified in different degrees among most of the Israeli population.

Physical Severance of Immigration. During the early days of Zionism, when people left their home country and went to Palestine, they had very few economic or technical means to revisit and keep contact with their former homeland. This created a physical distance which precluded the back-andforth movement necessary for psychological separation. In later years, the political situation prevented such revisiting, especially among the oriental Jews, who came from the Arab countries which were at war with Israel, and those from the Communist
Bloc which broke ties with Israel after the Six-Day War (Segev 1986).

Forced Severance Caused by the Holocaust. In addition to the physical severance, the Nazi extermination process eliminated any possibility for psychological separation for millions of Jews. The lucky émigrés (who fled Nazi occupation before the war) left behind homes, families', communities, and whole cultures that vanished as if they had never existed (Bar-On 1994). Survivors from the Nazi occupation who came after the war, being initially traumatized by the sudden forced severance from their parents, homes, and communities, traumatized further by the humiliation and annihilation at the hands of the Nazi regime, experienced their third and most severe traumatization in the form of the hollowness which they found in their home-setting after the war (Keilson 1992). Their fourth traumatization occurred when they were admitted as immigrants into Palestine, due to the British Mandate policy (Yablonka 1994). Their fifth traumatization occurred when they finally came to Israel and were judged and excluded by the local collective according to its own standards of heroism, blaming them for "lack of courage" to fight back Nazism (Segev 1992). As a result, many of the survivors silenced their experiences from the Holocaust. In turn, the silence and lack of possibility to mourn transmitted the traumatic effects of the Holocaust to their descendants and interfered with their resettlement processes (Davidson 1980).

Severance by Choice of the Zionist Ideology. Zionism qualified immigration to Israel in terms of good and the diaspora in terms of bad (Segev 1986). The term "to immigrate" to Israel was defined as "Aliya," which meant in Hebrew-to ascend. This term is still being used, just as emigrating abroad from Israel is still defined as "Yerida," or descent in Hebrew.

Also, instead of resettlement, one usually talks in Hebrew about "absorption," thereby implying that when making "Aliya" everyone becomes a part of one whole (Segev 1986), but never really clarifying what that means.

During the early years of the State of Israel, the ideological component was central to the collective. It included the revival of the Hebrew language, the linkage to the tradition of the people of Israel before they went to the diaspora (after the destruction of the Second Temple), and the vision of creating the "new Jews" who will go back to manual labour and earn their living from it. A narrative of heavy criticism of Jewish life in the diaspora evolved, accompanied by an idealistic wish to break off from it by the development of an Altnoiland-an old-new collective, independent of the one in the diaspora. Clearly, this ideology was the kernel of the non-psychological approach to resettlement in Israel. It proscribed any need for psychological separation which would have advised an ongoing connectedness to the home culture and people. Such an approach was labelled as "weakness" which should be overcome and disassociated from.

Severance of the Secular Trend of Zionism. Within the Jewish religious community some form of continuity, both in terms of tradition and in terms of family and community ties, was regarded as highly important.

This made it possible to ease a little, the different aspects of severance and provided more opportunities for psychological separation and mourning of the original home and culture. Also, going back to Zion has always been regarded as the ultimate wish for every religious Jew in the diaspora, and this is still the case with the last immigration waves from Ethiopia. It also gave a positive meaning to many of the hardships stemming from other aspects of severance. For the secular Jew, who had severed from religion, such softening mechanisms did not exist. Unless they were organized in new forms of communities (like kibbutzim), they had to confront the various aspects of severance by themselves, almost in anomie. This may account for the many suicides in the early days of Zionist immigration to Palestine (Segev 1986). 
Severance Due to the Hardships of Daily Life in Palestine and Later in Israel. The harsh reality of life in Palestine (disease, economic and social retardation, struggles with the Turks, the Arabs, and later with the British, the Arab states, and the Palestinians) preoccupied the mind and the body of most new immigrants of the early years and, to some extent, is still the verbalized norm today. Severance from the original culture became a fact of life, not only a perceived wish of an ideology; the two clearly reinforced each other. To devote time and energy for psychological separation had been seen in the 1920s and the 1930s as a luxury in a society in which few luxuries were available. However, this collective norm changed only to a limited extent when the luxuries of life became part of the Israeli culture. The non-psychological approach could not accommodate the easing of living conditions as a signal or as a justification of a more psychological approach to life, including a retroactive separation from (the almost forgotten) past culture and home. The discourse about the hardships of life now became a justification for ongoing severance-continuing the non-psychological approach of resettlement (Segev 1992).

To summarize, in the Israeli society severance became a reality as well as a mental construct: it created a collective narrative which reflected an interaction of the need, the must, and the wish. Within this narrative there were, however, many contradictions. As already mentioned, religion versus secularity was one of them. But even within this global theme there were many different variants. For example, the Oriental Jews have a Sephardic tradition which is different from the Ashkenazi one of European Jews. The European tradition is more principle-oriented and less people-friendly than the Oriental tradition (Bar-On 1986). In addition, many of the East European Jews broke off from their extended family for Zionist ideological reasons (or were forced to, owing to the Holocaust) as part of their immigration and resettlement. Some of them severed their ties with their extended family before they had left for Israel, owing to processes of modernization and secularization (Segev 1986). Quite a few of the Oriental Jews immigrated to Israel together with their extended families in the early 1950s. Still, for some of them, the family lost its authority structure in the process of immigration. Others, immigrating from the United States and South America, had more financial means and ability to go back and forth during their initial years in Israel. Each of these factors, and many others, affected the quality and total effect of severance or the feasibility for more or less psychological separation.

Confronted by a dense coalition of enemies, the Israeli society tried to show its relative strength by creating the image of a newly-born nation, flexible and creative, powerful in military and economic achievements. The culture, until they and their descendants adopted new, local signifiers. If possible, they revisited their home culture before they finally made the choice to resettle in Israel. However, they paid a certain price: not living up to the standards of the collective, they were looked down upon by the "real" Israelis who refrained from such visits (by choice, through compliance with the dominant norm, or because of external man-made catastrophes like the Holocaust).

\section{Severance Re-examined: \\ Transgenerational Transmission}

One could assume or claim that, owing to the powerful combination of necessity and ideology, severance would finally bring about successful resettlement and integration. Even if some emotional price had been paid for inadequate separation processing,

\section{To summarize, in the Israeli society severance became a reality as well as a mental construct: it created a collective narrative which reflected an interaction of the need, the must, and the wish. Within this narrative there were, however, many contradictions.}

young Israeli, with his open shirt, shorts, and sandals, looked wellrooted in this alien environment: Immigrants to the new state were trained to fit into this image: to learn Hebrew, adjust to the climate, tour the country, and join the army. The Israeli identity was basically that of a youth culture. It was characterized by Herzel's famous slogan: "If you wish it, it will not be a legend (but a reality)." The total identification with the Zionist ideology reinforced severance and its non-psychological perspective of resettlement.

During the early years (the 1920 s to the 1940s), when the collective narrative worshipped severance, there were also individuals who intuitively practised more adequate psychological separation, paying the price of social marginality. They spoke their native language with their children and their fellow people. They tried to maintain emotional contact with and adhered to the traditional signifiers of their home biological processes and reality are stronger than psychologists tend to acknowledge. One would then expect that the children or grandchildren of the severed immigrants would feel deeply rooted, because they no longer suffered from the same emotional ties or childhood memories as did their parents. However, we have quite a few examples that the opposite was true. The negative aftereffects of severance could be easily transmitted to the following generations through repressed, delegitimized, or inadequate mourning processes, through "untold" or silenced stories of idealization or of traumatic experiences (Bar-On 1994). For example, in kibbutzim, one can observe today that there are founders who were left alone (their descendants had left the kibbutz), while there are others whose extended families live with them in the same kibbutz. Among the former, we find founders who, paradoxically, invested most of their energy in building up the new 
society (practising and adhering to severance). Many of their descendants left the kibbutz and even emigrated from Israel. When interviewed, the latter relate their choice to their traumatic childhood, blaming their parents for the lack of attention they received in childhood, in comparison to those parents who were less fanatic about the kibbutz and more children-minded all along (Bar-On 1986).

Further, among families of Holocaust survivors, we see today a growing consciousness and legitimating to reconnect to their painful past. The grandchildren, even more than the children, feel the need to open up previously sealed-off topics that survivors had silenced for many years owing to subjective and collective reasons. We find families in which grandchildren go with their grandparents to visit their home setting abroad, even if no living family members still exist there (Bar-On 1994). This trend is associated with a new awareness of previous delegitimation of Holocaust survivors by the Israeli collective during the 1950s and 1960s, different from other forms of delegitimation of the Israeli collective (Segev 1992, Levi 1989).

In addition to legitimating and relinking oneself to roots from the past, there is also the quest to re-examine the previous ideology of severance. While some blame the parents for not allowing or enabling processing of separation (as in the case of the kibbutz descendants, above), others show more understanding for the harsh conditions which precluded the legitimating of separation and the lack of consciousness concerning its importance for resettlement. However, the narrative did not change from adhering to severance to adhering to separation. Some people still evaluate these new trends as "retreat" and "giving up" of the Zionist zeal (Meged, in Rabinowitch 1994). For more psychologically-minded people, the same trends are evaluated as compensating for inadequate processing from the past and "healthy," though difficult to achieve after all these years (Rabinowitch 1994).
Aroian (1990) suggested a psychological model for separation versus severance in the American context: Poles who revisited their home country, many years after they had emigrated, became more deeply engaged and rooted in their new context in the United States, when compared to Poles who did not bother to revisit the old country. She claimed that the former could test in reality fantasies about the "good old times" and thereby work through and let go of these fantasies. Levi examines the reasons for Moroccan Jews' visits to their original home setting. He provides a sociological perspective: they go to find their Moroccan roots and find their Israeli identity (Levi 1989).

We decided to examine these theories in the Israeli context. We interviewed 15 persons who revisited their countries of origin, in Morocco and Eastern Europe. ${ }^{3}$ We were interested in their motives, why and when they decided to go, how they experienced their visit, and how (if at all) it affected their life in Israel thereafter. The interviews were open-ended, asking the subjects to tell their life stories. They were further analyzed by methods of biographical and narrative analysis (Bar-On 1994). One should note that it was impossible to visit these countries for more than forty years. However, there is a difference between the emotional meaning of revisiting one's home setting after a Holocaust (like Poland), and revisiting a home setting which one had left by choice (or a mixture of threat, collective norm, and choice) like Morocco. This difference aside, there is also the difference of social status and social absorption in the Israeli society. While the Eastern Europeans were, and to some extent still are, the dominant stream in the Israeli society, ${ }^{4}$ the Moroccan Jews suffered humiliation during their immigration and social marginalization for many years thereafter.

\section{Summary of Three Interviews}

Rachel $^{5}$ was born in Uzbekistan shortly after World War II. She was eight months old when her family moved back to Poland, which they had fled from the Nazi persecution and extermination. When Rachel was twelve, her parents decided to immigrate to Israel. Rachel integrated very quickly into the Israeli society and culture. She did her best to become an Israeli in every possible sense. However, when she married (another JewishPolish émigré), she renewed her love for the Polish language, culture, and especially manners. Rachel developed a kind of parallel life in the two (Israeli and Polish) cultures. She and her husband decided to revisit Poland in 1989. Several additional visits in the former USSR followed, on a formal mission of the Israeli government. During these visits Rachel visited her home (birth) town and addressed her roots there.

The most striking theme in the interview with Rachel was her need for balance and integrity. However, the visits to Poland and Russia upset that balance. During her first visit to Poland, she first felt very much "at home" and was overwhelmed by her strong emotions. However, at some point, she suddenly shifted to the other extreme:

"[A]fter that a few days passed and all of a sudden I felt I did not want to see them, I was not interested in those disgusting Poles, they made me angry with their ugly manners. Everything was hypocritical, did not belong to me. I was not at all interested in the culture: Where am I and where are they!"

This visit strengthened her sense of belonging to Israel and she developed "patriotic, even nationalistic" feelings, which she had never had before. This was accompanied with a drastic change from admiration to rejection of the Polish culture. Rachel said she would never return to visit Poland, redefining her roots orientation towards Russia.

It seems to us as though Rachel had started her visit in Poland with one intention (to reconnect to her roots there) and suddenly shifted to the other extreme. Though we do not know exactly what caused the change, we hypothesize, based on analyzing her narrative, that the same factors which attracted her to the Polish herit- 
age (their manners and culture) suddenly became "disgusting" and "hypocritical" for her. She actually lost the sense of balance and integrity carefully maintained for many years and came out of that visit "more patriotic, even nationalistic" as an Israeli. In our interpretation, she suddenly backed off from the process of separation and mourning (perhaps it became too difficult for her), thereby increasing her psychological severance from her home culture, clinging now to her resettlement in Israel, a process probably similar to the one she experienced during her early years in this country.

Moshe (40) was born in Morocco and immigrated with his family to Israel in 1954 as a five-month-old baby. He grew up in a development town in the south of Israel. He became a lawyer, and was recently nominated as a judge. Moshe tried to become an Israeli according to the dominant norms of Western culture. He learned about the Moroccan culture mostly through the tales of his father. However, because of his father's poor economic status and feelings of deprivation in Israel, Moshe believed that his father "made it all up," glorifying and clinging to an imagined past to avoid the harsh reality of resettlement. Moshe learned to resent and disassociate himself from his father's stories.

In his mature years, having attained success socially and economically, and after the death of his father, Moshe felt a strong need to revisit his birthplace in Morocco. He went to Morocco three times, visiting the village where he was born. Each visit was characterized by a deeper penetration into the way of life and culture of the village. Moshe learned a lot about the heritage of his father's family and their importance in the life of the local Jewish community for generations. Moshe had to admit to himself that he had originally misjudged his father's stories about the latter's life in Morocco. This changed Moshe's attitude towards Jewish life in Morocco almost to the point of idealization. However, alongside with this new identification with the heritage of his father, Moshe also reported a "deeper sense of reconciliation" with his life in Israel.

In Moshe's case, we find traces of strong severance from his original heritage owing to the low status of his parents after immigration and resettlement, and his own wish to "make it" according to dominant (Western) norms. He disassociated himself emotionally from his father and the latter's "imaginary" tales about the good life in Morocco.

Unlike Rachel's, Moshe's visits to his home village helped him re-examine his roots (his relations to his father), and redefine his identity as a proud Moroccan Jew. This, in turn, added a new quality to his Israeli identity, as he could now mourn and separate from

diplomatic relations with the former USSR.

"I felt so strongly that I should go. I wrote all kinds of letters to Khrushchev, Bulganin and everyone else who had power at that time. I begged them to let me in, even for one day, so I could visit and sit at my father's grave." Eventually, in 1990 Joseph went to visit his home town and his father's grave, and subsequently revisited these places with his sister. He describes a sense of belonging and reconciliation with his life in Israel as a result of these visits. He plans to go on with these visits and also invite his children to join.

Joseph's severance was a sharp one and difficult to process. In an intuitive psychological sense, Joseph insisted

\section{One may not observe and become sensitive to the differences in their psychological processes of separation and resettlement until one analyzes their stories.}

his father and original homeland. Now he could feel as a proud Israeli not based only on (alien) dominant standards, but also based on his own JewishMoroccan origin. Still, Moshe is perhaps stuck in a new phase of idealization which may hamper further separation processes (Bar-On 1994). Levi (1989) reports of another possibility, closer to that which Aroian mentioned (1990): during the visit to Morocco, Moroccan Israelis have the opportunity to test their previous idealizations of their place of birth, thereby reorganizing their relationship to their past and present homeland.

Joseph was born in the Ukraine in 1929 and immigrated to Israel in 1949. After being absorbed in his new country, he studied, became a banker, and later a bank manager in central Israel. When Joseph was twelve years old, the Nazis had entered his home town and murdered his father before his eyes. This traumatic experience was incised in his memory in addition to his own traumatic experiences in the Holocaust. Of all the interviewees, Joseph stood out in his obstinate desire to visit his home town even before Israel had on working through the severance. He felt that only a visit at his father's grave would support such a process. The repeated visits facilitated the process of separation and mourning from his father, thereby also improving his reconciliation with life in Israel. We feel that his plans to go on with these trips (with his children) show that not just the process of separation from the memory of his murdered father is involved, but also other aspects of his original culture. Again, however, many more aspects of the past may have to be worked through, and we do not yet know if Joseph will be able to find the way and the time to handle them.

\section{Discussion}

Consequences of integrating the psychological approach of resettlement into therapy, education, and immigration policy making. It is to be emphasized that Rachel, Moshe, and Joseph may speak equally highly of their immigration and resettlement in Israel in their daily discourse. However, the previous analysis showed that, within this common narrative, there are many possibilities and undercurrents relat- 
ing to separation and severance. Each of these three persons recently revisited their original home setting. However, for each one it was a different experience, based on their personal life history and life story (Bar-On 1994). One may not observe and become sensitive to the differences in their psychological processes of separation and resettlement until one analyzes their stories. Still, these psychological integrative efforts have been constructed within a social context, in which the ideology and reality of severance are still dominant. The more we become sensitive to such ongoing needs of mourning and separation, the more we will also contribute to processes of reconciliation with life in Israel (Segev 1992).

We could learn from the interviews that the picture is complex. Revisiting one's old home setting stirs up strong emotional reactions. For some, like Joseph or Moshe, it had a healing effect of rebinding and opening up, while for others, like Rachel, it caused an emotional burden and closed up something. This difference could be accounted for by a variety of factors, such as their social status and support, their personal ripeness to move from severance to separation, and others. The rebinding may also yield new idealizations, which may in turn cause new forms of severance, unless processing separates into further steps (Bar-On 1994).

One could conclude that the possibility to integrate a more psychologically-oriented approach of separation into the reality and notion of severance should be applied carefully. Its application has, however, a wide range of potential settings: in therapy, in education, and in policy making. In therapy one could suggest that, if extreme severance during resettlement should be diagnosed (even among previous generations), careful processing of mourning and separation should be recommended. Here, one should be aware of the possibility of countertransference: therapists may suffer from the same problems of severance which their clients bring up in the therapeutic setting. This would require special attention on the part of the therapists as well as their clients. In education (where the same danger of counter-transference exists), one could suggest educational programs which may legitimize rebinding to the family's past, especially before immigrating including linguistic expressions, cultural habits, and family memories. One such program, though mostly poorly practised, was already formalized: the project of "family roots" in the sixth grade. However, many more such programs could be developed for different age groups, in literature, history, geography, and social sciences. In this connection, the trips of youngsters to Poland, as organized by the Ministry of Education under the heading of Linking to the Past, have been heavily politicized, and may even reinforce severance instead of separation (BarOn 1994).

Concerning immigration policy making (where counter-transference could happen as well), the psychological notion of separation demands a more prolonged attitude to absorption and resettlement. One has to consider the specific aspect of severance which each wave of immigrants brings with them. We saw that the religious are different from the secular, the wealthy from the poor, the Ethiopian from the Russian, all in terms of their specific combination of severance. Therefore, the support they need in terms of processing adequate separation should also be adequately developed. In summary, we advocate the possibility of separation in an Israeli reality and ideology of severance. We feel that avoiding this aspect of experience has caused many problems in the process of resettlement; we now have new opportunities to address these issues and resolve them, through the helping professions and through policy making.1.

\section{Notes}

1. This paper is part of a study on the issues of uprooting and re-rooting, conducted by the first author and supported by the Raab Center for the Study of the Holocaust and Redemption at Ben-Gurion University of the Negev. For correspondence please write to Professor Dan Bar-On, Department of Behavioural Sciences, Ben-Gurion University of the Negev, P. O. Box 653, Beer Sheva 84105, Israel.

2. The word "integrated" is problematic in the sense that one assumes a collective identity to be integrated into. This was clearly not the case during the 1950 s or even the 1960 s (Segev 1986).

3. The full report of the 15 interviews is now in preparation by the authors. Narrative analysis of the interviews was conducted by using the method of Prof. G. Rosenthal (1987).

4. Here one should be careful. As mentioned earlier, this was true especially for those who had immigrated in the 1920 s and 1930s. Those who came after the war (Holocaust survivors) also suffered from social judgment, based on the local norms of heroism (Yablonka 1994).

5. All names and personal details were changed to help maintain interviewees' anonymity. All interviewees gave their consent to be interviewed and cited in scientific reports.

\section{References}

Aroian, K.J. 1990. A model of psychological adaptation to migration and resettlement. Nursing Research, 39, 1.

Bar-On, D. 1986. The Pantomime's Stick. Tel Aviv: Meirav. (in Hebrew).

Bar-On, D. 1994. Fear and Hope: Life-stories of Israeli Holocaust Survivors, Three generations in a Family. Tel Aviv: Hakibbutz Hameuchad (in Hebrew). Harvard University Press (in press).

Davidson, S. 1980. The clinical effect of massive psychic trauma in families of Holocaust survivors. Journal of Marital and Family Therapy, 1, 11-21.

Eilon, A. 1976. Understanding Israel. New York: Behrman House.

Keilson, H. 1992. Sequential Traumatization among Jewish Orphans. Jerusalem: Magnes.

Levi, A. 1989. "To Morocco and back: Ethnic aspects of trips of Morocco Jews to their original homeland." Unpublished M.A. thesis, Hebrew University: Jerusalem.

Rabinowitch, D. 1994. "A network of gray colours: an answer to Aharon Meged's accusation against the new Israeli historians." Tel Aviv: Haaretz, June 15, p. b1.

Rosenthal, G. 1987. "Wenn alles in Scherben fallt..." Von Leben und Sinnwelt der Kriegsgeneration. Opladen: Leske und Budrich. (in German).

Segev, T. 1986. The First Israelis. New York: Free Press.

Segev, T. 1992. The Seventh Million. Jerusalem: Keter (in Hebrew).

Yablonka, H. 1994. Foreign Brothers: Holocaust Survivors in Israel 1948-1952. Tel Aviv: Yad Ben Tzvi and Ben Gurion University Press. J 
Continued from page 10/ From UNRWA ...

summary record of the 5 th meeting of the Advisory Commission and the Director with the Conciliation Commission, held in Beirut, 26 January 1951, p. 4; PRO/ 17 -FO371/91410/ EE1826/44, 14 December 1951, summary of discussion between the Israeli Ambassador, London, and the British Secretary of State; NA/RG84/Tel Aviv(1950-52)/Boxl4/Folder 571(PRWA)/5 June 1952/From: U.S. Ambassador,Tel Aviv, to: Secretary of State.

16. PRO/FO371/91401/EE1821/63, 2 April 1951, [Foreign Office] internal memorandum: Note regarding handing over refugee relief to $A$ rab governments; PRO/FO371/91403/EE1821/ 119, 30 October 1951, From: James Keen, UNRWA, Beirut, To: the Foreign Office, London.

17. PRO/FO371/82239/EE1823/13, 6 April 1950, From: British Legation, Damascus, To: the Foreign Office, London.

18. PRO/F0371/91404/EE1822/24, 30 March 1951, Finances for United Nations Relief and Works Agency, Memorandum by Sir Henry F. Knight, United Kingdom Delegation, Advisory Commission, UNRWA, Beirut.

19. PRO/FO371/82595/E1461/11/G, 4 July 1950 , Top Secret Foreign Office memorandum.

20. PRO/FO371/91404/EE1822/6, 17 January 1951, enclosing an UNRWA inter-office memo randum of 8 December 1950, p. 3; PRO/FO371/ 98489/EE1805/2, 18 July 1952, From: British Legation, Tel Aviv, To: the Foreign Office, London.

21. op.cit.,p. 8.

22. PRO/FO371/91411/EE1828/1, UNRWA monthly report for November 1950; PRO/ FO371/91411/EE1826/6, UNRWA Haifa monthly report for December 1950; NA/ RG84/Tel Aviv(1950-52)/Boxl4/ Folder 571(PRWA)/5 June 1952/From: the Ambassador,Tel Aviv, To: the Secretary of State; ISA/FM2406/17A/Israel Foreign Ministry/31 December 1952/Treatment of former Arab refugees in Israel, a report covering the period 4 September 1952-15 December 1952 by the International Organizations Section of the Foreign Ministry, Jerusalem.

23. PR0/F0371/91404/EE1822/22, 7 March 1951, Assistance to the Palestine refugees; note by the Secretary-General to the United Nations General Assembly; PRO/F0371/98505/ EE1824/21, 26 March 1952, Palestine Refugees, Foreign Office internal memorandum by T.E. Evans, Middle East Secretariat.

24. cf. PRO/F0371/91410/EE1826/14, 26 January 1951, UNRWA summary record of the 5 th meeting of the Advisory Commission and the Director with the Conciliation Commission held in Beirut, 26 January 1951.

25. PRO/F0371/91410/EE1826/44, 14 December 1951, summary of discussion between the Israeli Ambassador, London, and the British Secretary of State; NA/RG84/Tel Aviv(195052)/Box14/Folder 571(PRWA)/4 April 1952/ From: [Keeler]; Tel Aviv, To: the Secretary of State.

26. PR0/F0371/91410/EE1826/45, 19 December 1951, From: the Ambassador, UK Delegation to the United Nations General Assembly, Paris, To: the Foreign office, London; NA/ RG84/Tel Aviv(1950-52)/Box 14/Folder 571/ 20December 1951/From: the Ambassador, Tel Aviv, To: the Secretary of State.
27. PRO/F0371/91410/EE1826/42, [5 December 1951], suggested approach to Mr. Sharet; it is evident that the British Government shared these views.

28. UNRWA officials shared this rather positive picture of cooperation, see: PRO/FO371/ 91411/EE1828/14, UNRWA Haifa monthly report for January 1951; PRO/FO371/91410/ EE1826/14, 26 January 1951, UNRWA summary record of the 5th meeting of the Advisony Commission and the Director with the Concliation Commission, held in Beirut, 26 January 1951, p. 12.

29. PRO/FO371/91401/EE1821/71, 9 May 1951, From: Sir Henry F. Knight, United Kingdom Delegation, Advisory Commission, UNRWA, Beirut, To: the Foreign Office.

30. PRO/FO371/91708/ER1016/5, 8 May 1951.

31. NA/RG84/Tel Aviv(1950-52)/Box 14/Folder 571(PRWA)/4 April 1952/From: [Keeler], Tel A viv, To: the Secretary of State; PRO/FO371/ 98520/ EE18216/5, 6 May 1952, From: Sir Henry F. Knight, United Kingdom Delegation, Advisory Commission, UNRWA, Beirut, To: the Foreign Office, London.

32. PRO/FO371/91411/EE1828/14, UNRWA Haifa monthly report for January 1951; the Israeli takeover was completed only in 1952: see: PRO/FO371/ 98799/ER1016/3, 8 February 1952.

33. NA/RG84/Tel Aviv(1950-52)/Box 14/Folder 571(PRWA)/18 April 1952/From: [Keeler], Tel Aviv, To: the Secretary of State.

34. NA/RG84/Tel Aviv(1950-52)/Box 14/Folder 571(UNRWA, SECRET)/8 May 1952/From: the Secretary of State, To: U.S. Delegation, Amman.

35. NA/RG84/Tel Aviv(1950-52)/Box 14/Folder 571(PRWA)/14 May 1952/From: Minor, Beirut, To: the Secretary of State; NA/RG84/Tel Aviv(1950-52)/ Box 14/Folder 571(PRWA)/9 June 1952/From: the Ambassador,Tel Aviv, To: secretary of state; NA/RG84/Tel Aviv(1950-52)/Box 14/ Folder 571(PRWA)/9 July 1952/From: the Charge d'Affairs, Amman, To: the Secretary of State.

36. NA/RG84/Tel Aviv(1950-52)/Box 14/Folder 571(PRWA)/28 May 1952/From: the Ambassador,Tel Aviv, To: the Secretary of State; 28 May 1952, From: Minor, Beirut, To: the Secretary of State; NA/RG84/Tel Aviv(1950-52)/ Box 14/Folder 571(UNRWA)/ 20 May 1952/From: Bergus, Beirut, To: the Secretary of state; NA/RG84/Tel Aviv(195052)/Box 14 / Folder 571(PRWA)/19 June 1952/ From: the Secretary of State, To: the Ambassador, Tel Aviv.

37. ISA/FM2445/1/Israel Foreign Ministry/8 September $1952 /$ minutes of the Ministerial Refugee Affairs Committee.

38. ISA/FM2445/2A/Israel Foreign Ministry/9 November 1952/Internal memorandum of the International Organizations Section of the Foreign Ministry, Jerusalem.

39. ISA/FM2444/19/Israel Foreign Ministry/15 June 1949/From: Gershon Meron, Tel Aviv, To: Walter Eytan, Lausanne.

40. ISA/FM2445/2A/Israel Foreign Ministry/12 November 1952/comments of the Prime Minister's adviser on Arab affairs on the Internal memorandum of the International Organizations Section of the Foreign Ministry, Jerusalem.J
Continued from page 14/ The Absorption ...

lion Jews from the former Soviet Union in the past four years is a clear example.)

Nevertheless, the arrival of one million immigrants during the first decade was revolutionary in every respect. It was a demographic revolution, increasing the country's population by 250 percent. It was a psychological revolution, because it gave the young state a feeling of power. This immigration also brought about a social revolution, changing the composition of the population and making Israel more heterogeneous, less "European," and more "Mediterranean" and "Middle Eastern."

The arrival of one million immigrants also gave Israel a jumping-off point for the development of a large, modern agricultural sector and for the beginnings of modern industry.

The immigration made possible the establishment of hundreds of new villages and some 30 new towns. In this manner, the government was able to carry out its policy of distributing the population to all areas of the country.

We also discussed the enormous difficulties of immigrant absorption, as well as the mistakes whose scars remain to this day. It is an achievement, however, that the absorption of the immigrants was accomplished while maintaining rapid economic growth, with relatively low levels of inflation and unemployment.

Israel's first prime minister, David Ben-Gurion, made immigration and its absorption the highest national priority. He used his authority to make the subject a most prestigious cause, and turned immigration into the flagship of the state of Israel.

Soviet-Jewish Emigration and
Resettlement in the 1990s
Edited by
Tanya Basok and Robert J Brym
Available from:
York Lanes Press
York Lanes 351, York University
North York ON M3J 1P3

